DOI 10.37882/2223-2982.2020.04.21

\title{
ЦЕННОСТНЫЕ ОРИЕНТАЦИИ ЖЕНЩИНЫ КАК СУБЪЕКТА ОБЩЕСТВЕННОГО ПРОЦЕССА В ИСТОРИИ РОССИИ
}

\section{VALUE ORIENTATIONS OF WOMEN AS A SUBJECT OF SOCIAL PROCESS IN THE HISTORY OF RUSSIA}

E. Tolok

Summary: The article provides a comprehensive analysis of the history of the formation and development of women's value orientations. It is noted that in a certain period of time different value orientations prevailed, but some of them are traditional and, as a result, unchanged. In particular, such values as family, children, marriage, and spirituality are considered by the example of highlighting the image of a woman in printed publications. At the same time, the phenomenon of stereotyped thinking of society is revealed, in which the new value orientations of modern women are not recognized. It is indicated that women who focus on professional activities, personal development, and political careers are perceived quite negatively, and therefore, ways to overcome the situation are suggested. In particular, the author formulates and justifies the conclusion that today there is a need to create a new system of values, which is supported, including by women. The author encourages women to Express their opinions openly and to break down stereotypical relationships. It is noted that the rejection of template thinking is favorable for the entire society as a whole.

Keywords: value orientations, history, social community, value system, women, gender
K ак и все существующие явления объективной действительности, ценностные ориентации женщин, образующих социальную общность, детерминированы широкой совокупностью объективных и субъективных факторов.

В данном аспекте, под объективными факторами целесообразно понимать политические, правовые и иные фактические отношения, которые сформировались в обществе на том или ином этапе развития. Кроме того, сюда целесообразно отнести общественно-экономическую систему и общественно-политический строй, в рамках которого действует и живёт социальная общность, так как именно в данных условиях будут формироваться ценностные ориентации. Стоит учитывать, что под воздействием ряда объективных факторов в обществе неизбежно формируется определённая система ценностей, оказывающая влияние на становление ценностных ориентаций конкретной социальной общности, которая имеет место в данном обществе.
Толок Екатерина Сергеевна

Ассистент, Балаковский инженерно-технологический институт - филиал ФГАОУ ВО «Национальный исследовательский ядерный университет «МИФИ» tolokks@mail.ru

Аннотация: В статье проводится комплексный анализ истории становления и развития ценностных ориентаций женщин. Отмечается, что в определённый период времени превалировали разные ценностные ориентации, однако некоторые из них являются традиционными и, как следствие, неизменными. В частности, на примере освещения образа женщины в печатных изданиях рассматриваются такие ценности, как семья, дети, брак и духовность. Одновременно с этим, выявляется феномен шаблонного мышления общества, в рамках которого не признаются новые ценностные ориентации современных женщин. Указывается, что достаточно негативно воспринимаются женщины, акцентирующие внимание на профессиональной деятельности, личностном развитии и политической карьер, в связи с чем, предлагаются пути преодоления возникшей ситуации. В частности, формулируется и обосновывается вывод о том, что сегодня имеет место необходимость в создании новой системы ценностей, поддержка которой осуществляется, в том числе, со стороны женщин. Автор призывает женщин открыто выражать свое мнение и разрушать шаблонные связи. Отмечается, что отказ от шаблонного мышления благоприятен для всего общества в целом.

Ключевые слова: ценностные ориентации, история, социальная общность, система ценностей, женщины, гендер.

Одновременно с этим, система ценностей будет включать в себя оценку со стороны общественного мнения, а также самооценку фактических ценностных ориентаций общности в обществе или группы. В указанной ситуации, преобладают особенности индивидуально-личностной психологии женщин и психологии пола, оказывающие влияние на мотивы поведения личности, а также на формирование её ценностных ориентаций, что целесообразно рассматривать с точки зрения субъективного фактора.

Представляется вполне естественным, что положение и роль женщины, а также её ценностные ориентации меняются с течением времени. Основываясь на различных научных исследованиях по заявленной проблеме можно констатировать наличие ценностей, которые будут основными для женщин в любой период времени. Так, к данным ценностям относятся семья, образование, работа, карьера, здоровье, дети и духовность.

Особенности общности женщин видятся в том, что 
обладая общими социальными признаками, они выполняют такую уникальную и социально-необходимую роль, как роль матери. Представляется, что именно данная функция предопределяет роль женщины в современном социуме. Более того, выполняя данную функцию, женщина несёт в обществе определённую нагрузку идеологического характера. Можно заключить, что в обыденной общественной жизни модель идеальной материнской позиции имеет образ разумной и любящей матери.

В результате анализа работ многочисленных отечественных философов, писателей и историков можно констатировать, что женщины играют особую роль в оптимизации духовности и нравственности общества. Так, в своей книге «Условия абсолютного добра» Н.О. Лосский приводил многочисленные примеры данного факта. Рассматривая историю Натальи Долгорукой, которая последовала вслед за мужем в ссылку в Сибирь, автор анализирует записки графини, которая указывала: «войдите в рассуждение, какое мне это утешение и честна ли эта совесть - когда он был велик, так я с радостью за него шла, когда он стал несчастен, отказать ему? Я не имею такой привычки, чтобы сегодня любить одного, завтра другого» [1, с. 294].

В результате анализа подобных исторических примеров можно заключить, что русская женщина в дореволюционной России придерживалась таких канонов, как вера в бога, служение семье, верность, сохранение семейных традиций. Собирательным образом женщины в данном аспекте будет являться женщина, являющаяся хранительницей домашнего очага, женщина-мать $[2$, c. 88].

В начале XX века происходят достаточно существенные изменения в духовных и морально-нравственных ориентациях женщин нашей страны. В связи с этим, планомерно сформировалась принципиально новая социокультурная ситуация. Так, в советское время наблюдались изменения в системе установок и ценностей женщин, так как семья и дети начинают преобладать над ценностями духовного порядка. Одновременно с этим формируются и некоторые иные ценности, например, получение образования и работа как источник заработка. Полагаем, что данная ситуация во многом была обусловлена тем, что в данное время на территории страны происходила массовая ликвидация безграмотности, а также планомерное развитие культуры и образования. Ярким примером является лозунг, опубликованный в журнале «Крестьянка», датируемый 1925 годом. Так, в издании было указано; «женщина, учись грамоте, - это завет Ильича» [3, с. 40].

В результате сравнительного анализа изданий журнала «Крестьянка» прошлых лет можно проследить трансформацию образа женщины, а также изменение её стиля и ценностей. Так, в первой половине 20 века тематика журналов находилась под влиянием идеологии, а женщина предстаёт перед нами в образе сильной и мужественной гражданки, к которой едва ли можно применить фразу «слабый пол». Однако уже в 50-60-х годах прошлого века тематика журнала постепенно меняется, а женщины в нём изображаются в костюмах и платьях, а не в рабочей форме как ранее. Прорывными стали 70-е годы прошлого столетия, так как на страницах печатных изданий впервые начинают поднимать сексуальные темы. Кроме того, впервые публикуются фотографии женщин в купальниках, что целесообразно рассматривать через призму сексуальной революции на территории нашей страны.

В 80-е гг. тематика журнала меняется ещё больше. Несмотря на то, что журнал ещё достаточно пронизан идеологией, женщина всё чаще предстаёт не только в роли заботливой жены и матери, но и в роли настоящей женщины, которая любит и заботиться о себе. В связи с этим, в журнале появляются многочисленные статьи, посвященные отношениям полов, красоте и моде.

Особенная экономическая и политическая обстановка на территории нашей страны, которая имела место после распада СССР, породила неизбежные перемены в иерархической цепи установок и ценностей российской женщины. Так, на первый план в анализируемый период выходят работа, карьера и деньги, а также профессиональный и личный успех.

В 90-е гг. XX века на страницах журнала «Крестьянка» появляется многочисленная реклама, которая, так или иначе, формирует образ современной женщины. Так, рекламная продукция, представленная в журнале, позиционируется в качестве истинного символа женщины в связи с чем, обладание той или иной вещью позволит женщине быть ещё красивее и успешнее. Очевидно, что реклама подобного рода была рассчитана преимущественно на обеспеченных женщин, в связи с чем, многие женщины среднего достатка стремились к обладанию определённой вещью для поддержания образа красивой и успешной дамы.

Стоит отметить, что в нашей стране в рамках анализируемого периода прошли многочисленные структурные экономические трансформации, которые значительно изменили характер трудовой деятельности женщины и оказали влияние на формирование профессионально ориентированных стратегий. В связи с этим женщины оказались в новой рабочей среде, столкнувшись не только с определёнными возможностями, но и трудностями, что представляется вполне естественным. Более того, перемены социально-экономического характера породили дифференциацию и расслоение внутри женской социальной группы, изменили традиционное отноше- 
ние к семье и, как следствие, вызвали спад рождаемости в России. Новая социальная среда формируется в России и сегодня, так как на современном этапе развития к женщине выдвигаются новые требования, трансформируются содержание и диапазон социальных ролей, изменяется место женщины в социальной структуре общества. Например, сегодня меняются не сами ценности женщины, а иерархия данных ценностей, так как некоторые из них выходят на передний план, а некоторые, наоборот, уходят на задний план. Так, сегодня профессиональная деятельность женщины рассматривается не только как средство получения денежных средств, но и как основа личной самореализации и профессионального роста, что не было так ярко выражено в иные периоды.

В современных изданиях журнала «Крестьянка», который проходит нитью через настоящее исследование, женщина выполняет сразу несколько ролей, которые, подчас, откровенно навязаны средствами массовой информации. Так, сегодня идеализируется образ «женщины-звезды» и женщины, обладающей ухоженностью и красотой. Отдельный сегмент статей представлен публикациями о карьерном росте женщин и повышении её квалификации. Нельзя не отметить некое смещение социальных и профессиональных ролей, так как планомерно возрастает количество случаев, когда женщины работают на «истинно мужских» профессиях. Также активно развивается образ женщины, которая счастлива в браке несмотря на кризисные явления в институте семьи. В связи с этим, публикуются статьи под названием «как улучшить брак», «как вернуть любовь мужа» и так далее. Нельзя не отметить увеличение количества статей, посвящённых сексуальным вопросам, а также статей, обобщающих опыт других семейных пар в тех или иных ситуациях. Одновременно с этим, имеет место минимизация статей, идеализирующих образ женщиныматери, что является достаточно негативной тенденцией. Активно пропагандируется секс до брака, что ранее было запрещенной, если не сказать, одиозной темой [3, c. 44].

Стоит отметить, что в современном российском обществе преобладает формационный подход к пониманию сути женщины, а также её предназначения. В соответствии с данным подходом, женщина является полноценным работником, работающая наравне с мужчиной, которая выпадает из профессиональной деятельности только в период отпуска по уходу за ребенком. Одновременно с этим, женщина рассматривается как физически более слабый субъект трудовых правоотношений, в связи с чем, формируется перечень работ и должностей, которые женщина не может занимать. Можно констатировать, что формационная система ценностей изначально позиционирует женщину как не совсем выгодный и конкурентоспособный субъект трудовых и некоторых иных правоотношений.
Современная социально-экономическая ситуация на территории нашей страны такова, что профессиональная деятельность женщин во многом предопределена объективной необходимостью профессионального роста, а не получением материальных благ, что также имеет определённое значение. Так, женщины всё реже стремятся играть роль домохозяйки и хранительницы очага, желая реализовываться в профессиональном плане наравне с мужчинами. Усматривается прямая корреляция между женщиной, имеющей высшее образование и женщиной, которая стремится достичь определённых профессиональных и карьерных высот.

Рассматривая роль женщин в политической сфере, стоит отметить, что женщины в политике встречаются не так часто и такая тенденция является для нашей страны типичной. Полагаем, что во многом это обусловлено тем, что политика нередко рассматривалась через призму «грязного дела» в связи с чем, участие в ней женщин является не обязательным. На пути женщины к лидерству серьёзную роль играют препятствия, связанные с социализацией полов. Социализация женщин во многих странах мира, в том числе и в России, происходила и происходит таким образом, что у большинства из них не возникает особых амбиций по поводу карьерных и политических устремлений. Большинство людей не видят в низком политическом статусе женщин социальной несправедливости. С детства мужчин настраивают на то, что они будут работать, как минимум чтобы прокормить семью, а женщин - что их кто-то прокормит. И мужчина, не сделавший профессиональную карьеру до 30 лет, как и женщина, не сумевшая создать семью до 30 лет, могут считаться в обществе аутсайдерами.

Также в данном аспекте нельзя не отметить тот факт, что социальная судьба женщины на территории нашей страны предопределяется рядом так называемых «природных моментов». По существу их социальная значи $\neg$ мость сводится к семейным ролям, а они, в свою очередь, редуцируются к обслуживающим функциям. Если главное для женщины - семья, а работа для неё на втором месте, то и на работе она тоже оказывается на втором месте, выполняя подсобные, вспомогательные роли. При этом подразумевается, что работа может быть для женщины только «занятостью», но не профессией, а тем более карьерой. Ориентация женщин на профессиональную деятельность оценивается многими как неженственная или даже антисемейная.

Также в условиях нашей страны сформировалось устойчивое мнение, что женщины не так сильно ориентированы на карьеру и профессиональную деятельность как мужчины, ибо потребность в карьере ими не осознаётся и не является для них характерной. Однако согласиться с данной точкой зрения весьма затруднительно даже несмотря на то, что в практической деятельности 
карьерных высот ждут преимущественно от представителей мужского населения. В связи с этим, если женщина добивается опредёленных профессиональных успехов, нередко говорят о том, что женщине банально повезло и с её умениями или навыками это никоим образом не связано. Как следствие, успешность женщины измеряют её способностями завести и сохранить семью, а также родить и воспитать определенное количество детей. На этом фоне женщин нередко обвиняют в том, что они забывают своё истинное предназначение и утрачивают женственность тем, что стремятся к карьерным высотам. Полагаем, что указанное стереотипное мышление вызывает недоверие к руководящим способностям женщин, а также порождает комплексы у представительниц прекрасного пола. Можно заключить, что сравнительно небольшое количество женщин на руководящих постах обусловлено тем, что соответствующая ролевая модель в обществе до сих пор не сформирована, а стереотип о том, что карьера и женственность не совместимы, является достаточно распространенным. Одновременно с этим, некоторые женщины находят в себе силы и возможности для преодоления стереотипов подобного рода.

Представляется, что для модернизации роли и места женщины в рамках современного общества, объективной необходимостью является разработка системы ценностных ориентиров, которая направлена на формирование установок на высшие ценности. Суть данной системы состоит в том, что женщина, в первую очередь, должна рассматриваться как человек и только затем как женщина в своем первозданном виде. Полагаем, что указанная система ценностных ориентаций способна снизить напряжение в социуме посредством практики социального творчества, которая реализуется в определённых социальных инициативах женщин.

Более того, женщинам рекомендуется открыто выражать сомнение в том, что женщина имеет изначальное предназначение, не связанное с реализацией карьерных амбиций. Представляется, что отказ от стереотипов подобного рода благоприятно повиляет на всё общество в целом, так как избавит от шаблонности мышления и навязывания ярлыков.

Каждая женщина должна иметь возможность индивидуального выбора самореализации и в профессиональной сфере деятельности, и в семейно-бытовой сфере в форме параллельного или последовательного сочетания профессиональной деятельности и материнства. Свобода выбора, предоставляемая женщине обществом, ведёт к гармонизации всех общественных отношений. Гарантируя свободу выбора, мы сумеем в полной мере использовать те возможности созидания, которыми обладает «женский резерв».
Резюмируя всё вышеизложенное, хотелось бы отметить, что женская социально-демографическая общность имеет значительный социальный потенциал, практически не используемый в процессе становления цивилизованного общества в России. Значительную роль в формировании женской социально-демографической общности как субъекта общественного развития могут сыграть новые ценностные ориентации, способствующие становлению социогендерной идентичности женщин и снимающие социальное напряжение в социуме через практику социального творчества, реализуемого в социальных инициативах.

Женские социальные инициативы не разрушают устои общества, а предлагают их пересмотреть, исходя из парадигмы, в соответствии с которой представители обоих полов будут находиться в равных условиях. Равная с мужчинами степень свободы необходима женщинам не только просто для поддержания чувства собственного достоинства и возможности самовыражения во всех сферах жизни, она составляет основу формирующегося гражданского общества новой демократической России.

Обобщая всё вышеизложенное, мы делаем вывод о том, что ценности западной цивилизации под видом общечеловеческих навязываются российскому массовому сознанию. Следуя примеру западной культуры, российская культура превращается в общество комфорта, которое характеризуется стремлением к удобству в физической и экономических сферах, к легкости социальных отношений, к порядку в политике. Но при этом позитивное по смыслу, общество комфорта ориентирует человека на совокупность преувеличенных естественных человеческих потребностей, противостоящих его духовной природе. Преувеличение ценности данных потребностей подавляет человека, лишает его возможности выбора, лишает независимости. При этом все средства общества комфорта как по лекалу переносятся на российскую культуру с западной.

В целом западноевропейская традиция сформировала культуру, в которой предпочитают, любят сильных, удачливых, умеющих вовремя адаптироваться к изменяющейся ситуации. Такая культура - результат преимущественно мужской, новоевропейской традиции, когда человек стал надеяться больше на себя, чем на Бога, коллектив, Другого.

Сегодня обществом экономически и политически продолжают руководить мужчины, прибегающие к силе везде, где им кажется это необходимым, а женщины остаются в основном на вторых политических ролях. При этом ситуацию чаще всего реально не меняют эпизодические вхождения женщин во власть в разных социокультурных традициях, поскольку окружение и 
ценностно-мировоззренческий климат, пропитанный «духом мужчин», остаётся. Для существенных культурных сдвигов необходимы действительные радикальные изменения установок общества, иное отношение к женщине, признание женщины как изначальной ценности, проистекающее из её природы носителя эмоциональнодуховного начала. Чтобы обеспечить решение глобальных проблем, мужчины должны сами поставить вопрос о новой, более гармоничной модели цивилизации, учитывающей реальное положение женщин в мире.

1. Лосский Н.0. Условия абсолютного добра. - М., 1991. - 372 с.

ЛИТЕРАТУРА

2. Силласте Г.Г. Эволюция духовных ценностей россиянок в новой социокультурной ситуации / Г.Г. Силласте // Социологические исследования. - 1995. - № 10. - С. 88-95.

3. Петров М.С. Эволюция образа женщины в отечественной журналистике (на примере контент-анализа журнала «Крестьянка») / М.С. Петров // Вопросы культурологии. - 2010. - № 7. - С. 40-44.

4. Чиченкова С.Н. Ценностные ориентации женщин России в различные исторические периоды / С.Н. Чиченкова // Изв. Сарат. ун-та. Нов. сер. Сер. Акмеология образования. Психология развития. - 2010. - №2. - С. 44-48.

5. Овчинникова Е.А. Гендерная идентификация в российском культурном дискурсе: от средневековья к просвещению / Е.А. Овчинникова, С.А. Троицкий // Женщина в российском обществе. - 2019. - № 4. - С. 100-112.

6. Гунченкова Е.А. Ценностные ориентации женщин в контексте преодоления трудных жизненных ситуаций / Е.А. Гунченкова, Е.П. Кораблина // Психопедагогика в правоохранительных органах. - 2015. - №3 (62). - С. 63-68.

7. Силласте Г.Г. Гендерная социология и российская реальность. М.: Альфа- М., 2016. - 640 с.

8. Шишлова Е.Э. Гендер как инновационный научный и философский дискурс / Е.Э. Шишлова // Вестник МГИМО Университета. - 2013. - № 1 (28). - С. 148-152.

9. Бондаренко Л.Ю. Роль женщины: от прошлого к настоящему/ Л.Ю. Бондаренко // Общественные науки с овременность. - 1996. - № 6. - С. 163-170.

10. Боровкова И.В. Изменение социальных ролей мужчин и женщин, как феномен в современной культуре / И.В. Боровкова // Молодой ученый. - 2012. №4. - C. 512-514.

11. Кажаева А.А. Смысл жизни глазами женщины: материалы ХІІІ Международных гендерных чтений «Гендерные трансформации в современном мире» (Ростов-на-Дону, 25 марта 2016 г.) / под науч. ред. д-ра филос. наук Л.А. Савченко. - Ростов-на-Дону : Издательство Южного федерального университета, 2016. - C. $63-67$.

(c) Толок Екатерина Сергеевна (tolokks@mail.ru).

Журнал «Современная наука: актуальные проблемы теории и практики»

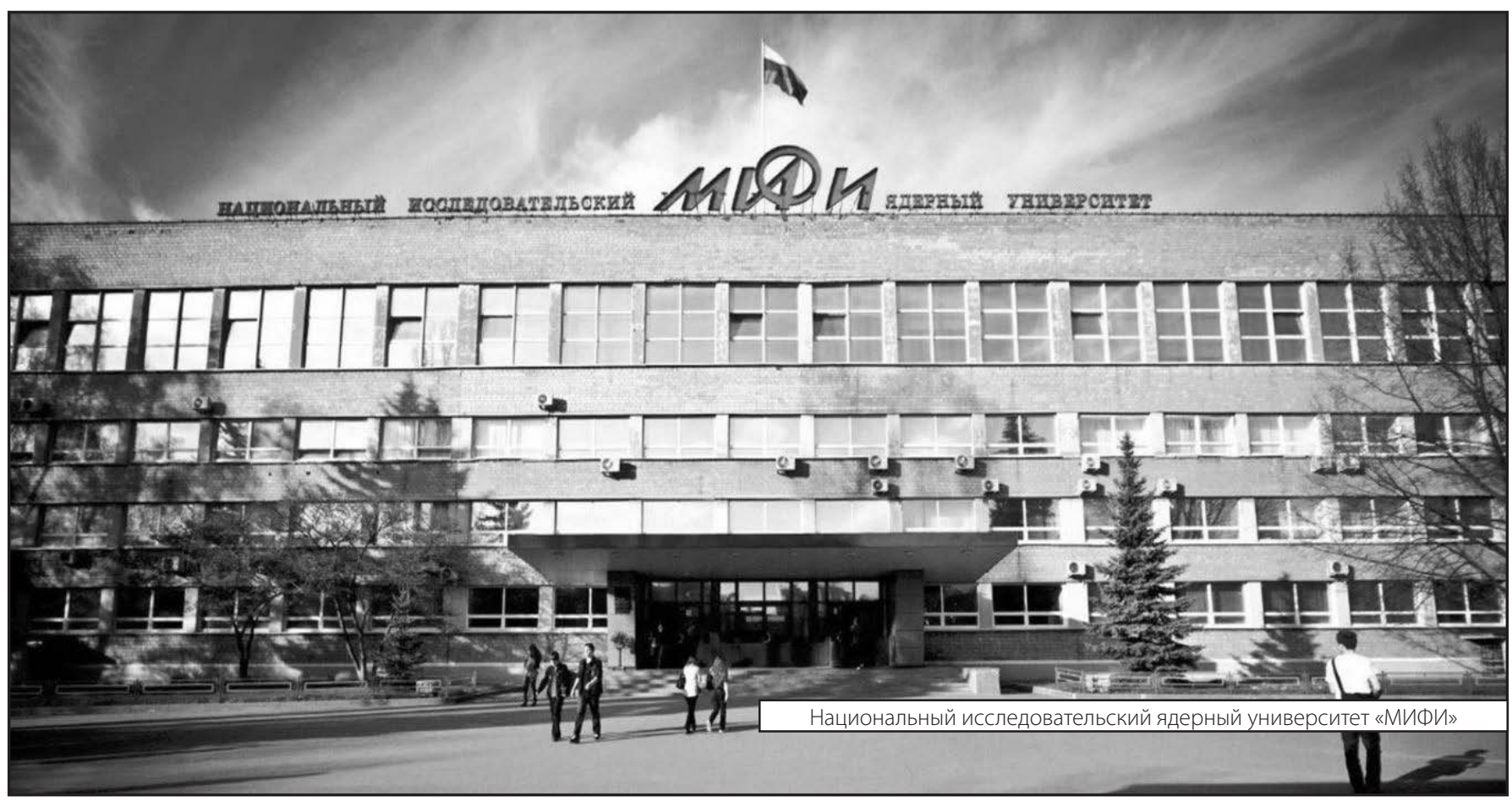

